\title{
ACUTE GYNAECOLOGICAL EMERGENCY CAUSED BY RUPTURED DERMOID
}

Sweta Lal' ${ }^{1}$, Alpana Singh ${ }^{2}$, Neerja Goel ${ }^{3}$

\section{HOW TO CITE THIS ARTICLE:}

Sweta Lal, Alpana Singh, Neerja Goel. "Acute Gynaecological Emergency Caused by Ruptured Dermoid". Journal of Evolution of Medical and Dental Sciences 2014; Vol. 3, Issue 21, May 26; Page: 5705-5710,

DOI: $10.14260 /$ jemds/2014/2653

INTRODUCTION: Benign dermoid cyst makes up 10 to 15 percent of all ovarian tumors and tends to occur at a relatively early age. Dermoid cysts are bilateral in 12 percent of cases. Cystic teratomas and mucinous cystadenoma may often coexist in the same ovary. A dermoid cyst rarely grows beyond the size of a melon. The lining epithelium is stratified squamous and the cyst contains sebaceous material within, they also contain ectodermal elements like sebaceous glands, hair follicles and sometimes teeth. There is no specific tumor marker in clinical practice for dermoid tumor. CA 125 elevation in seen with epithelial ovarian tumor. CA 19-9 is elevated in mucinous ovarian malignancy and in gastrointestinal cancers. CEA levels higher than $5 \mathrm{mg} / \mathrm{L}$ are seen elevated in mucinous cancers. Rupture of dermoid cyst is usually spontaneous but may occur from trauma or during labor, coitus or pelvic examination. Rupture is more likely if the wall of the cyst is already damaged by previous ischemic degeneration, if the cyst is papilliferous in type or if it is malignant. It presents with acute pain with the feeling of give away. There may be signs of peritoneal irritation.

KEYWORDS: Ovarian dermoid, rupture dermoid, tumor markers.

CASE REPORT: Mrs. X, 50 year old female presented to the OPD with complain of swelling of lower abdomen since last 10 years which had increased in the last 15 days. Patient had no other significant symptoms. She had history of pulmonary Koch's 30 years back for which she had taken antitubercular treatment for 9 months. She was postmenopausal since 6 years with previous normal cycles and smooth perimenopausal transition. In her obstetrics history, she was $\mathrm{P}_{6} \mathrm{~L}_{6}$, all full term vaginal deliveries at home with no antenatal or postnatal complications. Patient had no history of any contraceptive used ever.

On examination, she was thin built with good general condition. Her general physical examination was unremarkable. Her pulse was 90 per min and BP was 160/90 mm of Hg. On per abdomen examination there was a non-tender cystic mass of about 28 weeks arising from the pelvis with irregular contour but distinct borders with side to side mobility present. No venous dilatation was present. No free fluid could be appreciated. On local examination significant findings were, on per speculum examination there was a poly of about $2 \mathrm{~cm} * 2 \mathrm{~cm}$ coming from the endocervix. On per vaginum examination. Fleshy polyp felt arising from the endocervix. There was a cystic mass felt filling all the fornices. Uterus was felt anterior to the mass which was firm, normal in size. The mass was not moving with cervical motion. On per rectal examination, the same mass was again appreciated anteriorly, the rectal mucosa was free and no nodularity was felt.

Patient was worked up for ovarian tumor. All her routine investigations were normal.

Her tumor markers were as follows:
CA-125: $6195 \mathrm{U} / \mathrm{ml}$.
CA 19.9- $29003 \mathrm{U} / \mathrm{ml}$,
CEA- $43.63 \mathrm{ng} / \mathrm{ml}$,
CA 72.4- $1.99 \mathrm{U} / \mathrm{ml}$. 
Ultrasonography whole abdomen showed a senile uterus and a thick walled complex cystic mass with internal echoes seen occupying lower abdomen reaching well above umbilicus measuring $3000 \mathrm{cc}$ in volume likely cystic ovarian tumor. No evidence of free fluid. Other organs were normal.

Contrast enhanced computed tomography revealed a large hypodense cystic lesion with evidence of fat content in the non-dependent part measuring $19.4 \times 13.8 \mathrm{~cm}$ in size with evidence of peripheral wall calcification and loculation extending from pelvis to epigastrium. No solid enhancing lesion or no echogenic wall noted. Impression- dermoid cyst from left side, moderate ascitis. Other abdominal organs were normal.

On the basis of above investigations patient was prepared for staging laparotomy.

On the evening prior to her scheduled date for surgery, the patient developed severe pain lower abdomen, sudden in onset. There was no history of trauma. On examination, patient's general condition was average. There was no pallor. Her pulse was $110 / \mathrm{min}$ and BP was $102 / 60 \mathrm{~mm}$ of $\mathrm{Hg}$. On per abdomen examination a 24 week vague lump with no definite borders. There was presence of gross free fluid. There was marked tenderness on per vaginum examination with tenderness and fullness in all fornices. An urgent USG was done which revealed free fluid in the abdomen which was echogenic in nature with the ovarian tumor size decreased than before. USG guided tap was done. Cheesy material came out.

Diagnosis of ruptured dermoid was established and patient was taken up for emergency laparotomy.

Intraoperatively, about 2.5 litres of cheesy material was present in the peritoneal cavity, which was aspirated out. Some cheesy material was also stuck on the bowel, gall bladder, uterus, peritoneal surfaces and omentum. Large $(15 \times 10 \times 5 \mathrm{~cm})$ left sided ovarian dermoid was present which had ruptured (figure 1)

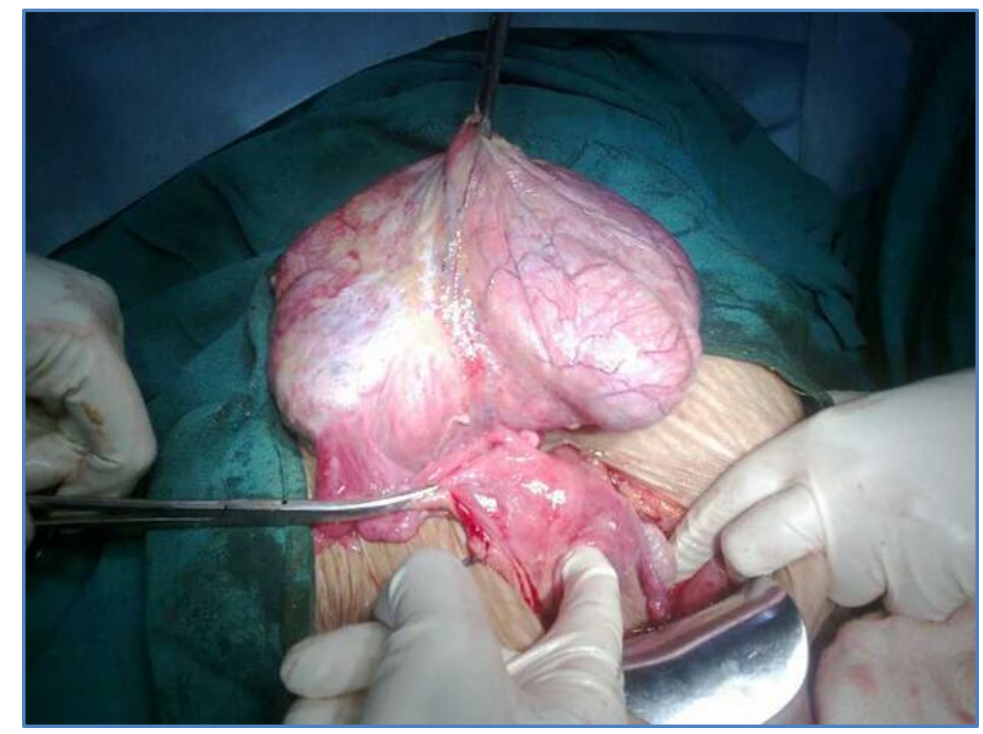

Fig. 1: Shows the intraoperative picture of the dermoid

Omentum was stuck to the site of the rupture. Total abdominal hysterectomy with bilateral salphingo-oopherectomy was done. Infracolic omentectomy was done. Other abdominal organs were 
inspected but there was no obvious sign of malignancy. Pelvic and para aortic lymph nodes were not enlarged. Intraperitoneal lavage was done to prevent peritonitis. On cut section (figure 2), the cyst had tuft of hair. Cheesy material present in the cyst. No solid areas were present.

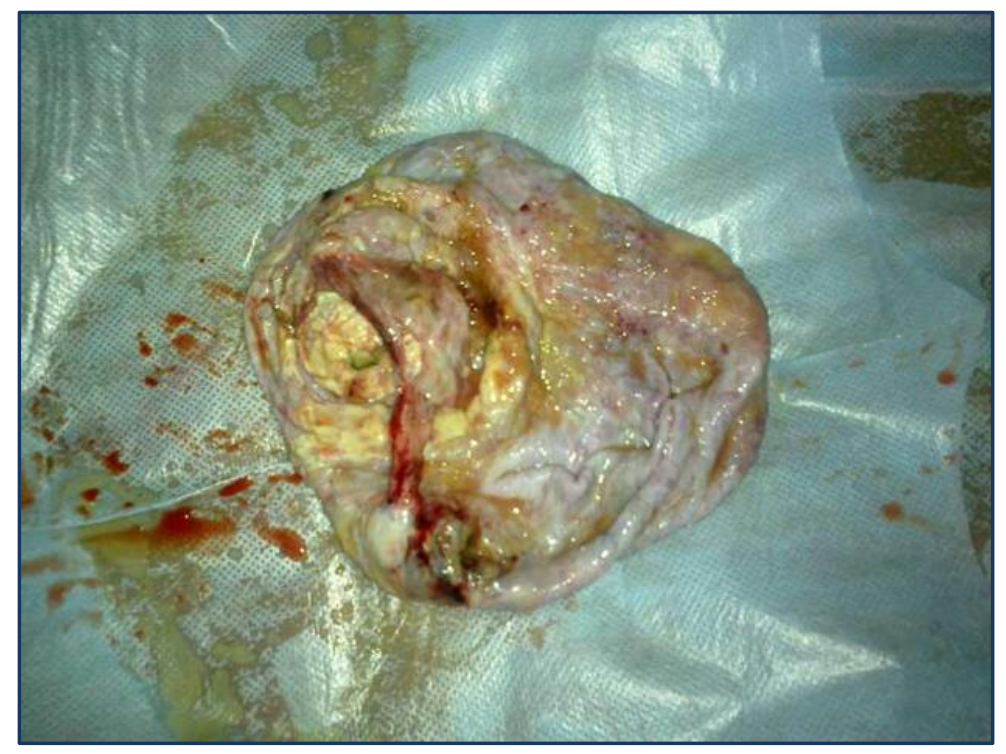

Fig. 2: Shows the cut section of the dermoid with cheesy material inside and presence of tuft of hair

Patient stood procedure well and was comfortable in her post op period.

Her ascitic fluid reports were as follows: no malignant cells seen on cytology, TLC- 13600 with $20 \%$ polymorphs and $80 \%$ lymphocytes. BACTEC \& AFB smear negative.

Histopathology report showed ruptured dermoid cyst of the ovary, with leiomyoma of the uterus with atrophic endometrium, chronic cervicitis with inflammatory cervical polyp. Section of the omental tissue showed congestion with small foci of hemorrhage and evidence of ruptured dermoid cyst.

On follow up, after 6 months, patient is doing well and her tumor markers are as follows:

CEA- 4.87

CA $125-30.9$

CA 19.9- 94.2 (99\% fall in value)

DISCUSSION: Spontaneous rupture of dermoid is a rare complication and is reported in only $03 \%$ to $0.7 \%$ of cases ${ }^{1}$. Most common complication seen with dermoid cyst is torsion of the cyst. Most of the studies ${ }^{2,3}$ have stated torsion as the most common complication associated with dermoid. Rupture is seen mostly with large tumors. Rupture of dermoid has also been previously reported mostly iatrogenically during surgery with incidence higher with laparoscopic approach than laparotomy, ${ }^{4}$ or rarely during labor and one rare case report of rupture due to procedure like oocyte retrieval. ${ }^{5}$ Numerous studies have reported chemical peritonitis following intraperitoneal rupture of a mature ovarian dermoid.6,7,8 Thorough Peritoneal washing and drainage after surgery is recommended to prevent chemical peritonitis. ${ }^{9,} 10$ 
Carbohydrate antigen 19-9 (also called as cancer antigen 19-9; sialylated Lewis (a) antigen) is mainly increased in gastrointestinal system tumors. It has also been reported to be elevated in some other malignancies and benign condition. In a study published in 2013 in Medical Science Monitor it was observed by Cho HY et al11 that mature cystic teratomas with CA19-9 elevation were correlated with a larger diameter $(8.53 \pm 3.84 \mathrm{~cm}$ vs. $6.95 \pm 3.97 \mathrm{~cm}, \mathrm{p}=0.002)$ and presence of fat component (67.1\% vs. $32.9 \%, \mathrm{p}<0.001)$, compared to those with normal CA 19-9. In addition, simultaneous elevation of CA125 and CA19-9 was associated with a higher probability of malignant neoplasm. According to Emin u et al, ${ }^{12}$ CA $19-9$ the mean tumor size of patients with elevated CA 19-9 was greater than those with normal CA19-9 level $(\mathrm{P}=0.01)$. There have been no reported cases of such high levels of CA 19-9 observed in any of these studies associated with benign ovarian dermoid. Burcu Artunc Ulkumen et $\mathrm{al}^{13}$ presented a case report of torsion of a dermoid with CA 19-9 level of $1983 \mathrm{U} / \mathrm{ml}$. He attributed the raised level of the tumor marker to torsion of the dermoid and tissue necrosis. Elevated CA 19-9 levels may also be caused by rupture of the dermoid cyst. ${ }^{14}$ A weakened cyst wall due to large diameter of the cyst may be another cause of the elevated CA19-9 level.14 Another case of ruptured benign ovarian cyst with ascitis had reported values of CA 19-9 as $2880 \mathrm{U} / \mathrm{ml}$. Such high values of CA 19-9 have never been previously reported in any benign ovarian tumor In the above mentioned case, the markedly high level of tumor markers were most probably because of the big size of the tumor or because of weakening of the cyst wall which later on caused spontaneous rupture of the cyst. It is possible however that the high serum CA19-9 was due to the resultant contact of cyst fluid with the peritoneum causing inflammatory ascites.

\section{LEARNING POINTS:}

- High levels of CA 19-9 could be associated with benign ovarian tumors: more extensive studies need to be done to establish positive correlation.

- High level of clinical suspicion is required to diagnose a ruptured dermoid cyst, especially if one has not examined the patient prior to rupture.

- Chemical peritonitis can be avoided even after massive spillage of the cyst contents by thorough peritoneal lavage and drainage.

\section{REFERENCES:}

1. Giustini FG, Sohn S, Khosravi H. Pelvic abscess and perforation of the sigmoid colon by a segment of benign cystic teratoma: an unusual complication of induced abortion. Journal of Reproductive Medicine. 1978; 20(5):291-292.

2. Pantoja E, Rodriguez-Ibanez I, Axtmayer RW, Noy MA, Pelegrina I. Complications of dermoid tumors of the ovary. Obstet Gynecol. 1975 Jan; 45(1):89-94.

3. Ugur MG, Ozturk E, Balat O, Dikensoy E, Teke S, Aydin A. Do high levels of CA 19-9 in women with mature cystic teratomas of the ovary warrant further evaluation? Eur J Gynaecol Oncol. 2012; 33(2):207-10.

4. Long-Yun Ye, Jing-Jing Wang, Da-Ren Liu, Guo-Ping Ding, Li-Ping Cao. Management of giant ovarian teratoma: A case series and review of the literature. Oncol Lett. Oct 2012; 4(4): 672676.: Published online Jul 9, 2012. doi: 10.3892/ol.2012.793 


\section{CASE REPORT}

5. Coccia ME, Becattini C, Bracco GL, Scarselli G. Acute abdomen following dermoid cyst rupture during transvaginal ultrasonographically guided retrieval of oocytes. Hum Reprod. 1996 Sep; 11(9):1897-9.

6. Gendre J, Sebban-Rozot C, Régent D, Ranchoup Y, Ridereau-Zins C, Vullierme MP, Laurent V. Peritoneal parasitic teratoma and chemical dermoid peritonitis. J Radiol. 2011 May; 92(5):38292. doi: 10.1016/j.jradio.2011.03.005. Epub 2011 Apr 29.

7. Rubod C, Triboulet JP, Vinatier D. Ovarian dermoid cyst complicated by chemical peritonitis. Case report. Gynecol Obstet Fertil. 2007 Jul-Aug; 35(7-8):651-3. Epub 2007 Jun 29.

8. Gendre J, Sebban-Rozot C, Régent D, Ranchoup Y, Ridereau-Zins C, Vullierme MP, Laurent V. [Peritoneal parasitic teratoma and chemical dermoid peritonitis]. J Radiol. 2011 May;92(5):382-92. doi: 10.1016/j.jradio.2011.03.005. Epub 2011 Apr 29.

9. Hursitoglu BS, Demirtas GS, Demirtas O, Akman L, Yilmaz H. A clinico-pathological evaluation of 194 patients with ovarian teratoma: 7-year experience in a single center. Ginekol Pol. 2013 Feb;84(2):108-11.

10. Godinjak Z, Bilalović N, Idrizbegović E. Laparoscopic treatment of ovarian dermoid cysts is a safe procedure. Bosn J Basic Med Sci. 2011 Nov; 11(4):245-7.

11. Cho HY, Kim K, Jeon YT, Kim YB, No JH. CA19-9 elevation in ovarian mature cystic teratoma: discrimination from ovarian cancer - CA19-9 level in teratoma. Med Sci Monit. 2013 Mar 29; 19:230-5. doi: 10.12659/MSM.883865.

12. Emin U, Tayfun G, Cantekin I, Ozlem UB, Umit B, Leyla M. Tumor markers in mature cystic teratomas of the ovary. Arch Gynecol Obstet. 2009 Feb; 279(2):145-7. doi: 10.1007/s00404008-0688-2. Epub 2008 May 28.

13. Artunc Ulkumen B, Goker A, Pala HG, Ordu S. Abnormal Elevated CA 19-9 in the Dermoid Cyst: A Sign of the Ovarian Torsion? Case Rep Obstet Gynecol. 2013;2013:860505. doi: 10.1155/2013/860505. Epub 2013 Jun 11.

14. Atabekoğlu C, Bozaci EA, Tezcan S. Elevated carbohydrate antigen 19-9 in a dermoid cyst. International Journal of Gynecology and Obstetrics. 2005; 91(3):262-263. 


\section{CASE REPORT}

\section{AUTHORS:}

1. Sweta Lal

2. Alpana Singh

3. Neerja Goel

\section{PARTICULARS OF CONTRIBUTORS:}

1. Senior Resident, Department Obstetrics and Gynaecology, Guru Teg Bahadur Hospital and University College of Medical Sciences.

2. Assistant Professor, Department Obstetrics and Gynaecology, Guru Teg Bahadur Hospital and University College of Medical Sciences.

3. Professor and Director, Department Obstetrics and Gynaecology, Guru Teg Bahadur Hospital and University College of Medical Sciences.

\section{NAME ADDRESS EMAIL ID OF THE} CORRESPONDING AUTHOR:

Dr. Sweta Lal,

Dr. Lals Hospital, Kadru Road, Kadru, Ranchi-834002, Jharkhand.

E-mail: drsweta2004@gmail.com

Date of Submission: 10/04/2014. Date of Peer Review: 11/04/2014. Date of Acceptance: 18/04/2014. Date of Publishing: 22/05/2014. 